\title{
A literature review on dynamic pricing of electricity
}

\author{
Goutam Dutta $^{1 *}$ and Krishnendranath Mitra ${ }^{2}$ \\ ${ }^{1}$ Department of Production and Quantitative Methods, Wing 03, Indian Institute of Management, \\ Vastrapur, Ahmedabad, Gujarat 380 015, India; and ${ }^{2}$ Department of Business Management, University of \\ Calcutta, 1, Reformatory Street, Kolkata, West Bengal 700 027, India
}

Revenue management and dynamic pricing are concepts that have immense possibilities for application in the energy sector. Both can be considered as demand-side management tools that can facilitate the offering of different prices at different demand levels. This paper studies literature on various topics related to the dynamic pricing of electricity and lists future research avenues in pricing policies, consumers' willingness to pay and market segmentation in this field. Demand and price forecasting play an important role in determining prices and scheduling load in dynamic pricing environments. This allows different forms of dynamic pricing policies to different markets and customers depending on customers' willingness to pay. Consumers' willingness to pay for electricity services is also necessary in setting price limits depending on the demand and demand response curve. Market segmentation can enhance the effects of such pricing schemes. Appropriate scheduling of electrical load enhances the consumer response to dynamic tariffs.

Journal of the Operational Research Society (2017) 68(10), 1131-1145. doi:10.1057/s41274-016-0149-4;

published online 14 December 2016

Keywords: dynamic prices; demand and price forecasting; demand elasticity; willingness to pay; market segmentation; scheduling of load

\section{Introduction}

Dynamic pricing is one of the emerging areas of research in the retail electricity industry. It is a demand-side management technique that can reduce peak load by charging different prices at different times according to demand. According to the (CIA World Factbook) Cia.gov (2016), in 2012, the installed capacity for power generation in the USA was 1.063 million MW, whereas that of a rapidly growing economy like India was $254,700 \mathrm{MW}$. If we assume $5 \%$ of the installed capacity catering to only peak demand, then $53,150 \mathrm{MW}$ in the USA and 12,735 MW in India are the peak load capacities. If we consider (U.S. Energy Information Administration) Eia.gov (2016) data for capital costs of a natural gas-driven power plant, we find that huge investments of about USD 54.37 billion in the USA and USD 13.03 billion in India are trapped in installing such peak load capacities. Peaks in load profiles are the result of unregulated demand, and huge capacity addition is required to meet peak load. This peak load capacity stays idle during off-peak periods resulting in a loss of opportunity cost and system efficiency. Dynamic pricing can shift the demand from peak to off-peak and help avoid large capital investments.

*Correspondence: Goutam Dutta, Department of Production and Quantitative Methods, Wing 03, Indian Institute of Management, Vastrapur, Ahmedabad, Gujarat 380 015, India.

E-mail: goutam@iima.ac.in
Retail electricity markets generally offer flat pricing or block pricing. Prices remain unchanged irrespective of demand in the first case, while in the second, the per unit rate of electricity either increases or decreases with increasing slabs of electricity consumption. However, the costs of generation to meet peak demands are high as compared to those for off-peak demand, since most peak time generating units have higher operating costs than base load units. Thus, the abovementioned electricity prices do not reflect the true costs of generation and distribution. Although flat rates offer uncertainty-free electricity bills to customers, these lead to costly capacity additions. In addition to the reduction in peak demand, dynamic prices also provide each consumer with an opportunity to reduce his/her electricity bill at a constant consumption level, just by changing the consumption pattern by shifting the load.

Revenue management and dynamic pricing are economically and technically effective operational research tools successfully implemented in various industries like travel and leisure, telecommunications and online retail. However, real-time dynamic prices are not widely used in the retail electricity sector. A literature review on the multiple aspects of dynamic pricing of electricity has not been done earlier. In this paper, we try to address that gap with a survey of 109 published works that deal with multiple aspects of dynamic pricing. While the review is extensive, it is not exhaustive.

Decisions like how to optimize prices, consumption schedules, number of market segments, use of energy storage and 
generation schedules open up several research opportunities in the field of operational research.

We have addressed the following question in the survey: What are the different aspects related to the dynamic pricing of electricity?

From this survey, we can draw the following inferences:

1. Although academicians and researchers see the study of dynamic pricing of electricity as useful and interesting, regulators, suppliers and customers have stayed away from large-scale deployment of this concept. There are doubts regarding the potential benefits over the costs of implementation and possible excessive high bill values to customers.

2. Dynamic pricing can be useful to customers in terms of monetary savings. Suppliers can find it useful because of reduction in peak capacity investments, better planned operations and cost-reflecting prices. Dynamic pricing can help producers postpone investment decisions by shifting peak loads from peak to non-peak hours.

3. The feasibility of the application of dynamic prices depends on:

(a) cheap but efficient technology,

(b) well-educated and supportive customers and regulators, and

(c) well-designed pricing schemes with proper identification of market segments.

The technological issues can be addressed with the present state of technological developments. However, educating the markets on the benefits of the concept is also necessary. Further, the identification of market segments along with suitable pricing schemes and supporting programs is necessary for successful implementation.

4. Market acceptance of dynamic pricing can only be achieved if its benefits to each stakeholder can be proved. This requires more and more well-planned pilot projects and a study of different aspects involved in this field.

5. Pilot implementations show that dynamic pricing can elicit customer response and help in the reduction of bill value. Renewable energy usage shows a further reduction in the bill value by around $35 \%$. However, the elasticity of demand for electricity is low. Several demographic and environmental factors can improve demand response when coupled with appropriately designed dynamic prices. Enabling technology is useful in implementing dynamic prices and is found to be helpful in enhancing demand response.

6. Consumption scheduling models are required with enabling technologies to further enhance demand response, and several such models are proposed in many studies. Electricity markets can be segmented based on demographic and behavioral factors as suggested by some researchers, but these concepts have not been tested practically. Customers' willingness to pay for electricity can be useful information while designing pricing policies. Research shows that customers can pay 1.5 times the market price for better electricity services.

This paper is organized as follows. A review of studies on the applications and analysis of dynamic pricing in electricity is followed by discussion on various issues relating to dynamic prices in electricity. These include electricity pricing policies, retail and wholesale market pricing, forecasting of price and demand, elasticity of demand, customers' willingness to pay, the effect of enabling technologies, electricity market segmentation and consumption scheduling. Finally, the conclusion is followed by a listing of future avenues of research in this field. A list of references used in this paper is provided at the end. Table 1 and Figure 1 provide a snapshot of the references used in this paper. In our survey, a majority of the literature is from the USA. Our review also includes literature from the UK, China and India, as well as other countries in Asia and Europe.

\section{Applications and analysis of dynamic pricing in electricity}

Analyses of practical electricity data and pilot projects on dynamic pricing show that price and income elasticity of demand for electricity are low, but several lifestyle and behavioral factors can significantly enhance the demand response. Some researchers find dynamic pricing to be quite effective in stimulating a high level of demand response where they observe about $30 \%$ peak load reduction. Customers are more likely to reduce rather than reschedule consumption. The best responses are received during hot climates and from high consumption customers. Enabling technology is found to be very helpful in implementing dynamic pricing. Pricing schemes vary from market to market in order to stimulate the best response, and often supporting programs need to be implemented to eliminate customers' fear of excessive expense.

Mak and Chapman (1993) survey 14 utilities in the USA during 1980-1990 s. They note that the price designs are onepart and two-part with day-ahead hourly prices. Customers respond well to high prices and achieve over $30 \%$ reduction in peak hour consumption. They find that customer satisfaction depends on bill savings, control over costs, reliability in price notifications, notice time, greater price certainty and service by the company. Customers get dissatisfied with inadequate notice and equipment failure. Customers who wish to continue with real-time pricing prefer better status reports and price updates, access to usage data and the availability of longer contract periods.

Bose and Shukla (1999) examine the econometric relationship between electricity consumption and other variables at a national level in India with data covering more than 9 years. They find that electricity consumption in commercial and large industrial sectors is income elastic, while in the 
residential, agricultural, and small and medium industries, it is income inelastic. Tiwari (2000) studies household survey data from India and confirms that short-run income and price elasticity of demand are low and the upper-middle class provides maximum response price signals. Filippini and Pachauri (2004) develop three electricity demand functions, one for each season, from real data of 30,000 households in India. Results show that electricity demand is price and income inelastic but varies with household, demographic and geographical variables.

Charles River Associates (2005) reflect on case studies from China, Thailand, Tunisia, Turkey, Uruguay and Vietnam that relate to the implementation of dynamic price schemes (mostly TOU) in these countries. The paper concludes that: (1) Rates should benefit both-the utility and the consumers. (2)

Table 1 Distribution of the referenced literature based on country

\begin{tabular}{lclc}
\hline Country & No. of papers & Country & No. of papers \\
\hline Australia & 4 & Japan & 1 \\
Belgium & 1 & Netherlands & 2 \\
Brazil & 2 & Nigeria & 1 \\
Canada & 2 & Norway & 2 \\
China & 9 & Portugal & 2 \\
Denmark & 3 & Spain & 2 \\
France & 1 & Switzerland & 1 \\
Germany & 3 & Thailand & 1 \\
Greece & 2 & Tunisia & 1 \\
Hong Kong & 1 & Turkey & 3 \\
Hungary & 2 & UK & 10 \\
India & 7 & Uruguay & 1 \\
Ireland & 1 & USA & 49 \\
Italy & 1 & Vietnam & 1 \\
\hline
\end{tabular}

Shorter-duration peak periods enable higher customer acceptance of the rate. (3) A significant peak-to-off-peak ratio (3:1 or higher) is necessary for sufficient load reduction and bill savings. (4) Monitoring the impact of rates and modifying accordingly enhances customer satisfaction and cost-effectiveness. Faruqui et al (2009) study various experimental findings in the USA and note that sampling should consider an estimate of net benefit of implementation, cost of experimentation, good probability of making the right decision, and internal and external validity of collected data. They propose the gold standard of experimental design which includes control groups and treatment group/groups and pre- and post-data. They propose simple, revenue neutral and cost-reflecting rate design, short peak period, strong price signal and opportunity for significant bill saving.

Allcott (2009) studies a real-time pricing pilot in the USA that indicates that households emphasize on energy conservation rather than substitution. Welfare gains over the costs of installing metering infrastructure seem likely but not certain. Borenstein (2007) shows significant transfers in switching from a flat rate to real-time pricing from customer-level billing data for 1142 commercial and industrial consumers in Northern California. Most of the consumers observe from $4 \%$ reduction to $8 \%$ increase in the bill amount. Implementation of real-time pricing seems difficult if a supporting program to compensate the worse-off cases is not employed. Letzler (2007) performs an econometric analysis of data from California Statewide Pricing Pilot that reveals that customer response to prices varies widely among different customers. Hot days and customers who heavily use air conditioners provide the greatest response.

Faruqui et al (2009) analyze five dynamic pricing programs ( 3 of these are pilot and 2 are full-scale deployments) in the

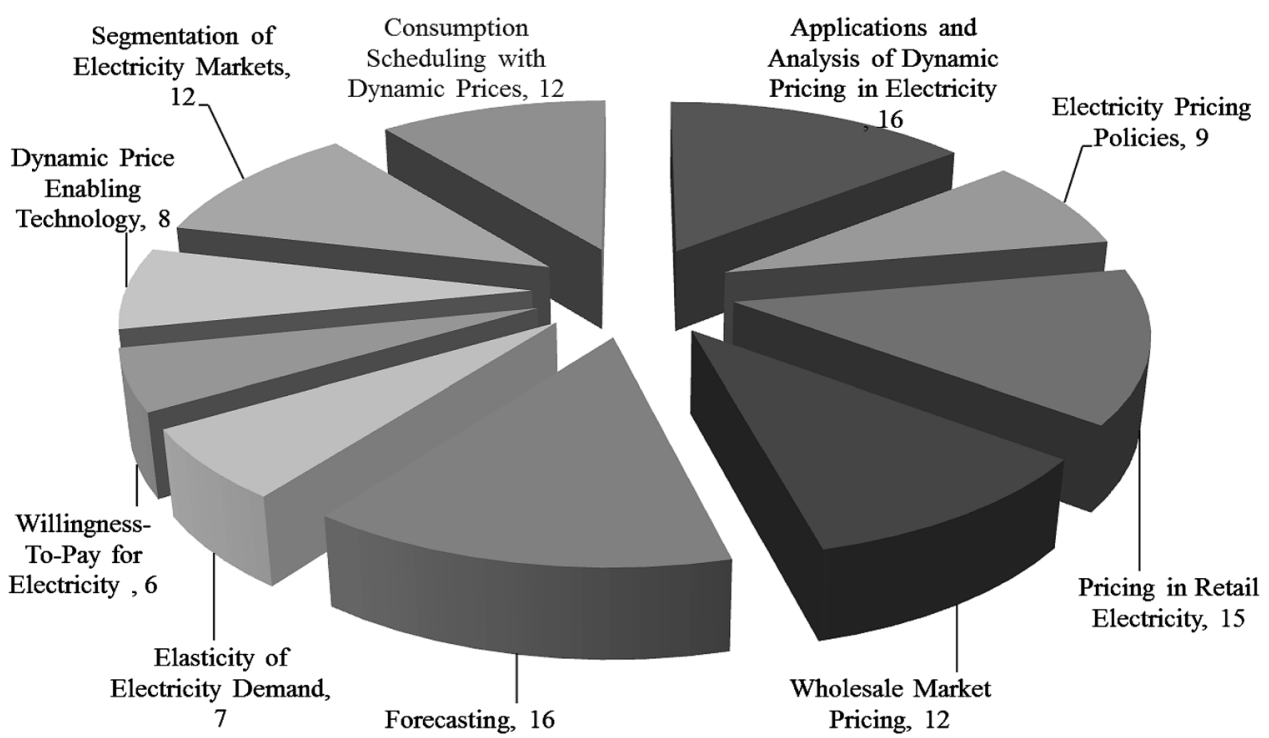

Figure 1 Distribution of surveyed references in the different sections of this paper. 
USA and show that customers respond positively to price signals regardless of utility or region. Use of enabling technologies provides greater chances of favorable demand price response. There is no universally best pricing scheme applicable to all conditions. Abreu et al (2010) observe 15 households in Portugal for 270 days in an interdisciplinary study using electronic meters. They recognize the need for knowledge about customer characteristics and behavior. Although the sample size is small, the authors find potential for improvement of energy efficiency from large consumer appliances. Borenstein (2013) uses stratified random samples of residential consumers of two largest utilities in California to study the likely impact of his proposed approach of opt-in dynamic pricing. He shows that most customers will benefit from critical peak pricing and real-time pricing and lowincome households will not be hurt by such tariffs. Zhou and Teng (2013) find low price and income elasticity of demand for urban residential demand in China. Lifestyle and demographic variables play a significant role in explaining electricity demand.

Faruqui and Sergici (2013) observe a large variation of demand response in data from 163 pricing treatments in 34 projects across 7 countries in an international database 'Arcturus.' The demand response depends on the ratio of the peak and off-peak prices. The response curves are nonlinear. Consistent results show that dynamic pricing can modify load profiles. Faruqui et al (2014) show that customers' response to dynamic prices increases with enabling technology. Price responsiveness is higher in hotter climates. Residential customers respond better to dynamic prices than commercial and small industrial customers. 'Hardship Low-Income Customers' respond less than others mainly because their consumption is low and indispensible, leaving them with no opportunity to reduce their consumption any further. Pagani and Aiello (2015) develop an experimental system to realistically stimulate dynamic prices and the services of a smart grid using data from wholesale markets and renewable energy setups in Netherlands. Results show average monetary savings of 35 and $20 \%$ while using dynamic prices with renewables and without renewables, respectively. The energy savings in both the cases are $10 \%$.

\section{Electricity pricing policies}

Joskow and Wolfran (2012) state the contributions of Fred Kahn, an academician and a regulator, in the 1970s, toward the promotion of time-varying cost-based pricing policies for regulated services like electricity. They describe that opportunities for implementation of dynamic pricing opened up with the evolution of competitive wholesale markets, development of cheaper two-way communication technologies and promotion of the concept by the policymakers themselves. They refer to the inferences of several dynamic pricing experiments and note that consumers respond well to TOU (time of use) and critical peak pricing. They suggest that the fear of large redistribution of expenditure is the largest impediment to the implementation of dynamic pricing policies.

Electricity pricing policies can be static or dynamic. Static prices do not change with a change in demand, whereas dynamic prices change with changing demand situations. Faruqui and Palmer (2012), Simshauser and Downer (2014) and Quillinan (2011) describe various pricing policies as mentioned below.

a. Flat tariffs: The price remains static even though power demand changes. Consumers under such a scheme do not face the changing costs of power supply with a change in aggregate demand. Thus, consumers have no financial incentive to reschedule their energy usage. They do not face any risk of high-value electricity bills for any unavoidable or unplanned electricity consumption. Hence, this scheme is often used as a welfare pricing scheme.

b. Block Rate tariffs: This scheme differentiates between customers based on the quantity of electricity consumption. The scheme consists of multiple tiers characterized by the amount of consumption. Inclining rate schemes increase the per-unit rate with increasing consumption and declining schemes do the opposite.

c. Seasonal tariffs: These schemes observe different rates in different seasons to match the varying demand levels between seasons. Energy is charged at a higher rate during high-demand seasons and the price lowers during lowdemand seasons.

d. Time-of-use (TOU) tariff: These are pre-declared tariffs varying during the different times of the day, that is, high during peak hours and low during off-peak hours. Such schemes can stay effective for short or long terms. This is also known as time-of-day (TOD) tariff.

e. Superpeak TOU: It is similar to TOU, but the peak window is shorter in duration (about four hours) so as to give a stronger price signal.

f. Critical peak pricing $(C P P)$ : This is a dynamic pricing scheme in which prices are high during a few peak hours of the day and discounted during the rest of the day. The peak price remains same for all days. It gives a very strong price signal and enhances the reduction of excessive peak load.

g. Variable peak pricing (VPP): This is quite similar to CPP with the only difference that the peak prices vary from day to day. The consumers are informed about such peak prices beforehand.

h. Real-time pricing (RTP): This is the purest form of dynamic pricing and the scheme with the maximum uncertainty or risk for the consumers. Here the prices change at regular intervals of $1 \mathrm{~h}$ or a few minutes. The change in the price in such small intervals increases the efficiency of the pricing scheme in reflecting the actual costs of supply, but such schemes require advanced technology to communicate and manage these frequent 
changes. Retail electricity markets may find it difficult to practice this scheme due to the high rate of data collection and transfer.

i. Peak time rebates (PTR): These rebates are just the opposite of CPP schemes. Rebates are provided for consuming below a certain predetermined level during peak hours and can be redeemed at a later time.

Figure 2 shows the relative risk-reward situations between the schemes described above from the consumers' point of view. There are two connected bar charts in Figure 2: The top one shows reward and the bottom one (inverted) shows risk. Figure 2 is inspired from Faruqui (2012).

Faruqui and Lessem (2012) analyze some policies based on factors like economic efficiency, equity, bill stability and revenue stability and prepare a scoring matrix to compare these policies. This is represented in Table 2.

Their assessment identifies RTP as the best policy with respect to all factors except for 'bill stability.' In order to minimize bill risk for customers in RTP, they propose policies like consumer baseline, price ceilings and floors, participation threshold, bill protection, educating consumers and the use of enabling devices. Borenstein (2009) also emphasizes RTP with price protection plans as the best policy for medium and large consumers. Dynamic pricing policies are preferred over flat pricing as these are more effective in providing economically efficient incentives for customers.

Kok et al (2014) note that electric utilities will prefer investment in renewable energy if there is flat pricing and not peak pricing. They verify the same with real data from Texas. However, peak pricing leads to a higher investment in solar energy in the case of diesel generator users. Costello (2004) notes that dynamic pricing policies are mostly voluntary and inefficiently designed because regulators are concerned over their fairness and the benefit over cost of implementation. They also doubt some customers' price responsiveness, which can lead to high average prices. Utilities are concerned over possibilities of customer complaints leading to revenue loss, non-recovery of the cost of implementation and possibilities

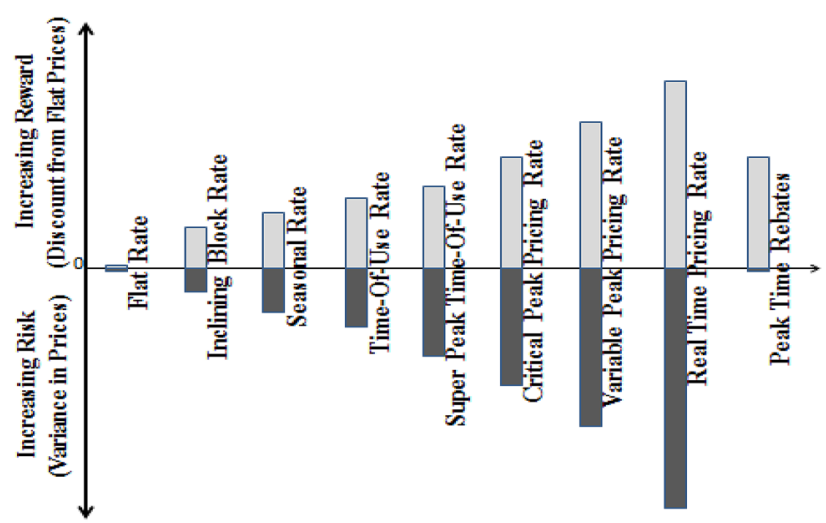

Figure 2 Risk-reward mapping of dynamic tariff types. that all gains from such implementation may be passed on to the consumer.

\section{Pricing in retail electricity}

Dynamic pricing can offer better results than flat pricing. Desai and Dutta (2013) prove that dynamic pricing is economically more efficient than traditional flat rate prices since it absorbs consumer surplus, thereby enhancing total revenue at existing costs, and reduces peak loads. Celebi and Fuller (2012) demonstrate that total surplus is more for TOU pricing than flat pricing under different market structures. Borenstein and Holland (2003) show that flat rate prices are economically inefficient and suggest that in order to improve economic efficiency, the share of RTP customers needs to be increased. However, they note that having more consumers within RTP schemes does not necessarily reduce investments for increasing capacity. Faruqui (2010) relates to a study which states that real-time pricing can induce peak demand reduction of $10-14 \%$, resource cost reduction of $3-6 \%$, market-based customer cost reduction of $2-5 \%$ and a social welfare increase by \$141-\$403 million in a year. Hledik (2009) reports a smart grid simulation of US power systems that estimates $5 \%$ reduction in annual $\mathrm{CO} 2$ emission and $11.5 \%$ peak reduction by 2030. Holland and Mansur (2008), however, argue that RTP reduces load variance but may actually increase emission. The effect on emission depends on the type of power generating units in use.

Harris (2006) describes a way of deriving the price of electricity by indexing it against a weighted average of present and past wholesale rates. David and Li (1993) state that both concurrent prices and prices at other times affect the demand response to dynamic tariffs, thus demonstrating the crosselasticity of demand. They develop theoretical frameworks that address the price formation problem with the crosselasticity of demand under certain conditions. Skantze et al (2000) show that delay of information flow between different markets causes price variations. Prices are correlated only if the markets are connected by transmission lines which are not congested.

Stephenson et al (2001) mention that variations in electricity pricing schemes may depend on several factors like thermal storage, combined heat and power generation, auto-producers, photovoltaics, net metering, small hydropower plants, dynamic tariffs, renewable energy, green tariffs and consumer characteristics like consumption pattern. Garamvölgyi and Varga (2009) show that prices can be designed by using artificial intelligence techniques to classify consumers based on procurement costs. Holtschneider and Erlich (2013) develop mathematical models based on neural networks for modeling consumers' demand response to varying prices. Their model is used to identify an optimal dynamic pricing through the Mean-Variance Mapping Optimization method. Seetharam et al (2012) develop a real-time 
Table 2 Comparison of the various pricing policies

\begin{tabular}{|c|c|c|c|c|}
\hline Policy & Economic efficiency & Equity & $\begin{array}{l}\text { Bill stability (risk to } \\
\text { vulnerable consumers) }\end{array}$ & Revenue stability \\
\hline Flat rate & Very poor & Very poor & Very good & Poor \\
\hline PTR & Good & Poor & Very good & Very poor \\
\hline CPP & Good & Average & Average & Good \\
\hline TOU & Good & Good & Average & Average \\
\hline $\begin{array}{l}\text { One-part RTP } \\
\text { (only variable) }\end{array}$ & Very good & Very good & Very poor & Good \\
\hline Two-part RTP (fixed + variable) & Very good & Very good & Poor & Very good \\
\hline
\end{tabular}

self-organizing pricing scheme, called Sepia, to compute the unit price of electricity based on consumption history, grid load and type of consumer. This pricing scheme is decentralized, and a grid frequency is used for grid load measurement in smart meters for determining the subsequent unit price of electricity. McDonald and Lo (1990) mention that an appropriate social basis of price designs for retail electricity includes welfare considerations for both consumers and suppliers. Li et al (2003) express the price-deriving objective as a nonlinear optimization problem leading to welfare, yet reflecting the competitive relationship among generation companies, utilities and customers.

\section{Wholesale market pricing}

Electricity is traded in a wholesale market for industrial customers and electricity retailers. A gap, however, remains between the wholesale prices and the retail prices. Generally, it is noticed that the price increases in the wholesale market are transmitted quicker to the retail market than price decreases. Johnsen and Jess-Olsen (2008) compare the different lags in retail prices from wholesale prices and the respective margins in four Nordic countries. Mirza and Bergland (2012) calculate that a 2.5 -Ore/kWh one-time increase in the wholesale market in Norway leads to asymmetric costs of $2.28 \mathrm{NOK}$ (more than 91 times the per $\mathrm{kWh}$ value) per average customer and a complete passthrough of wholesale price to retail price can take almost five weeks. Giulietti et al (2010) find that one-third to half of an increase in wholesale price is passed to the retail price in England and Wales.

Kirschen et al (2000) illustrate a method of determining wholesale market price through bidding. The lowest bid price is set by the supplier based on its costs of supplying a quantity of electricity for a future time period. Then, a pool of bid prices is accepted from bulk buyers. The selection of the bids is done from the highest priced one, in the order of decreasing prices, till the cumulative demand matches the supply. The last accepted bid price from the pool of selected bids sets the market price. However, the key price design decisions can depend on factors like contract pricing or compulsory pool pricing, one-sided or two-sided bids, firmness of bids or offers, simple or complex bids, price determination timing with respect to actual delivery, capacity payments, geographically differentiated pricing and price capping.

David and Wen (2000) conduct a review of literature to discuss bidding by individual participants to maximize their individual profits. They also discuss the role of regulators in limiting possible market abuse by some participants. The survey reveals that oligopoly, and not perfect competition, exists in the market, due to certain characteristics of the electricity market that restrict the number of suppliers. Different methods and ideas are used to model bid prices, which we discuss now. Li et al (1999) represent electricity trade as a two-level optimization process. A priority list method through a 'centralized economic dispatch' (CED) is used in the top level. The lower level has subproblems of decentralized bidding. Here, hourly bid curves are developed for the CED by using self-unit scheduling based on parametric dynamic programming. Both the levels focus on revenue maximization rather than on cost minimization. Zhang et al (2000) develop bidding and self-scheduling models using probability distributions and Lagrangian relaxation, respectively. Weber and Overbye (1999) use a two-level optimization problem to determine the optimal power flow considering social welfare. They determine a Nash equilibrium along with a market price with all participants trying for individual profit maximization.

Krause and Andersson (2006) use agent-based simulators to demonstrate different congestion management schemes such as market splitting, locational marginal pricing and flow-based market coupling. The welfare aspects of different pricing schemes are analyzed in these methods to arrive at suitable market power allocations. Zhao et al (2010) explain that the 'bid cost minimization' technique, generally used in the wholesale market, actually provides a much higher cost than the minimum bid cost. The authors use game-theoretic approach and propose that 'payment cost minimization' is a better technique from the consumer welfare point of view as it directly minimizes the payment made by consumers. Zhao et al (2008) further introduce transmission constraints in the problem, making it complicated but more realistic. Han et al (2010) use CPLEX's MIP for this problem to find low efficiencies. They overcome this problem through the 'objective switching method' in which the feasible region is reduced 
Table 3 Forecasting methods

\begin{tabular}{ll}
\hline Forecasting method used & Paper references \\
\hline Dynamic regression model & Nogales et al (2002), Zareipour et al (2006) \\
Transfer function model & Nogales et al (2002), Zareipour et al (2006) \\
ARIMA model & Contreras et al (2003), Taylor (2003), McSharry et al (2005), Zareipour et al \\
& (2006), Mirasgedis et al (2006), Wang et al (2009), Taylor (2010) \\
Artificial neural network technique & Mandal et al (2006), Catalao et al (2006), Saravanan et al (2012) \\
Kernel-based method & Kekatos et al (2013) \\
Principle component analysis-based method & Taylor et al (2006) \\
Exponential smoothing model & Taylor (2003), Taylor et al (2006), Taylor (2010) \\
$\varepsilon$-insensitive loss function support vector regress & Wang et al (2009) \\
model & \\
Trigonometric gray prediction approach & Zhou et al. (2006), Akay and Atak (2007) \\
Semi-parametric additive model & Hyndman and Fan (2010)
\end{tabular}

by performance cuts to minimize infeasibilities and improve efficiency.

\section{Forecasting}

Forecasting is an integral part of revenue management. Designing of dynamic prices requires forecasts of future demand, and scheduling consumption requires forecasts of future prices. Forecasting thus provides a platform for planning for the future in case of dynamic tariffs for all concerned parties. This section describes research on price and demand forecasting in the electricity sector. Table 3 shows the different methods used for forecasting price and demand.

\section{Price forecasting}

Retail price forecasts help consumers to preplan their consumption in a dynamic pricing environment, whereas wholesale price forecasts assist buyers and sellers in planning for bidding strategies. Nogales et al (2002) develop forecasting models based on dynamic regression and transfer function approaches. The authors use data from Spain and California with high levels of accuracy. However, Contreras et al (2003) find reasonable errors with the application of ARIMA models on the data from the same markets. Zareipour et al (2006) use ARIMA models to forecast Ontario's hourly prices from publicly available market information with significant accuracy, failing only to predict unusually high or low prices. Mandal et al (2006) observe improved forecasting accuracy by using the artificial neural network computing technique based on the similar day approach. They identify time factors, demand factors and historical price factors that impact price forecasts. Catalao et al (2006) note that neural networks for next-day price forecasting display sufficient accuracy for supporting bidding strategy decisions. Kekatos et al (2013) examine the Kernel-based day-ahead forecasting method and prove its market worthiness.

\section{Demand forecasting}

Electricity suppliers can better plan their supply and generating capacities with appropriate demand forecasts. Demand can be forecasted daily, weekly, monthly or annually. Short-term load forecasts from minutes to several hours ahead are required for controlling and scheduling power systems. Long-term forecasts help in planning investments, overhauls and maintenance schedules. Taylor et al (2006) compare the accuracy of six univariate methods for forecasting short-term electricity demand and find that simple and more robust methods (i.e., exponential smoothing) outperform more complex alternatives. The complex methods are seasonal ARIMA, neural networks, double seasonal exponential smoothening and principal component analysis (PCA). Taylor (2003) implements double seasonal Holt-Winters exponential smoothening for within-day and within-week seasonality. This method proves to be more effective than ARIMA and the standard Holt-Winters method for short-term demand forecasting. They correct the residual autocorrelation by using a simple autoregressive model. Taylor (2010) incorporates the within-year seasonal cycle as an extension of the double seasonal model. This triple seasonal model performs better than the double seasonal model and the univariate neural network approach. Wang et al (2009) demonstrate reduced errors in forecasts done by feeding a single-order moving average smoothened data to a $\varepsilon$-SVR ( $\varepsilon$-insensitive loss function support vector regress) model.

Mirasgedis et al (2006) incorporate weather influences in the medium-term electricity demand forecasts that can range up to 12 months. Meteorological parameters, like relative humidity and temperatures (that affect electricity demand), are used along with an autoregressive model to reduce serial correlation for four different climatic scenarios. Zhou, Ang and Poh (2006) show that the trigonometric gray model (GM) prediction approach (a combination of GM $(1,1)$ and trigonometric residual modification technique) can improve the forecasting accuracy of GM (1,1). Akay and Atak (2007) predict Turkish electricity demand using gray prediction with 
the rolling mechanism approach that displays high accuracy with limited data and little computational effort. Hyndman and Fan (2010) use semi-parametric additive models that estimate relationships between demand and other independent variables and then forecast the density of demand by simulating a mixture of these variables. McSharry et al (2005) provide probabilistic forecasts for magnitude and time of future peak demand from simulated weather data, as real data are unavailable. Saravanan et al (2012) apply multiple linear regression and artificial neural networks with principle components to forecasts made in India. They use eleven input variables and show that the second method is more effective.

\section{Elasticity of electricity demand}

A clear idea of the demand-price relationship or elasticity is helpful for effective demand-side management (DSM). Borenstein et al (2002) explain that elasticity of demand can be short run as well as long run. In short-run elasticity, we describe the price response from the system with its current infrastructure and equipment. In long-run elasticity, we consider the investments that can be made in response to higher prices during a longer time span. Wolak (2011) observes that electricity markets mostly have low elasticity of demand, at least in the short run. Dealing with low-demand elasticity leads to the implementation of large price spikes in spot pricing markets. He concludes that consumer response is roughly similar for short hourly peaks and longer periods of high price. Ifland et al (2012) reveal a steep slope of the demand curve from a study of the German electricity market. However, this field test proves that dynamic tariffs can increase demand elasticity and demand curves are more elastic during winter and less elastic during summer. Kirschen (2003) also observes that implementation of dynamic pricing definitely increases the elasticity of demand. He further notes that demand curves are steep, and shift, depending on the time of day or day of week. Shaikh and Dharme (2009) explain the seasonal variation of the load curve with TOU tariffs in the Indian context.

Kirschen et al (2000) study the short-term price response in the electricity market of England and Wales. In this case, halfhourly prices are announced $13 \mathrm{~h}$ in advance. The authors study cross-elasticity of demand along with self-elasticity. Cross-elasticity is measured as the rate of change of demand for one time period with respect to a change in the price of another time period. They form a 48 by 48 matrix of elasticity coefficients. They further establish that the consumer reaction to a price increase in the short run is rare unless the price increase is significantly high. This low-demand response can be because of consumption scheduling that involves some relatively cumbersome technology. The authors observe that consumers respond more to short-term price hikes than to short-term price drops. They develop a nonlinear elasticity function from this study. However, Braithwait (2010) explains that there can be no particular formula for determining the amount of demand response, which varies across customer types, events and types of price structures.

\section{Willingness to pay for electricity}

Designing any dynamic pricing scheme requires knowledge about the consumer's willingness to pay (WTP) for electricity and associated infrastructure. Devicienti et al (2005) study a TERI report that uses the contingent valuation method to determine the WTP for additional service features like reliability of supply. However, a portion of the respondents did not believe in the possibility of the improved scenario projected by the hypothetical market used in this process. Consumers find it difficult to comprehend electricity consumption in terms of KWh. Thus, the study phrases consumption in terms of 'appliance capacity' or 'hours of use' of each appliance. Stated choice experiments can be helpful in this case. Twerefou (2014) uses the contingent valuation method in Ghana and discovers that consumers' WTP is 1.5 times more than the market price of electricity. The author identifies significant factors that influence households' WTP through an econometric analysis of the data from this study. Ozbafli and Jenkins (2013) study 350 households in North Cyprus using the choice experiment method. They indicate that the electricity industry can experience an annual economic benefit of USD 16.3 million by adding $120 \mathrm{MW}$ capacity, since consumers are ready to pay more for uninterrupted power supply.

Gerpott and Paukert (2013) estimate the WTP for smart meters using responses from 453 German households obtained through online questionnaires. The authors use variance-based 'partial least squares structural equation modeling and find that 'trust for data protection' and 'intention to change usage behavior' are the most influential factors for WTP. An et al (2002) calculate Chinese consumers' WTP for shifting from firewood to electricity. They use stated preference data from personal interviews to estimate the parameters of a binary logit model from a random utility model. The authors calculate the probabilities of adopting electricity at different prices. Oseni (2013) explains that the ownership of a backup generator significantly increases the WTP for reliable grid supply in Nigeria. The author uses event study methods and discovers that the higher cost of backup generation with respect to the stated WTP amount causes this behavior.

\section{Dynamic price enabling technology}

Dynamic pricing enabling technologies help in dealing with price and quantity signals. These technologies provide effective communication of signals to consumers and sometimes also provide a suitable automated response from them. 
Technology helps in speeding up operations and enables efficient implementation of dynamic prices. Ifland et al (2012) conduct a field test in a German village that represents $50 \%$ of German living conditions. Consumers respond to flexible prices even without the aid of home automation, but automation technology is required to increase night-hour consumptions. Faruqui and Sergici (2009) examine the evidence from 15 dynamic pricing experiments and reveal that the magnitude of response of retail electricity customers to pricing signals depends on factors like 'extent of price change,' 'presence of central air conditioning' and 'availability of enabling technologies'. Thimmapuram and Kim (2013) note that consumers overcome technical and market barriers by using advanced metering infrastructure (AMI) and smart grid technologies that improve price elasticity. Kaluvala and Forman (2013) state that smart grid technologies can transfer load from peak to offpeak and reduce overall consumption without reducing the level of comfort. Quillinan (2011) elaborates that information communication technology (ICT) in a smart grid system increases the electric grid's efficiency. Applications like 'appliance control,' 'notification,' 'information feedback' and 'energy management' make enabling technologies essential in demand response programs.

A typical electricity supply curve is nonlinear with increasing positive slopes. The benefit of demand response measures can be best observed at the steeper parts of the supply curve. Faruqui and Palmer (2012) analyze the data of 74 dynamic pricing experiments and find that the amount of reduction in peak demand increases with the increase in the peak to offpeak price ratio, but at a decreasing rate. They derive a logarithmic model and check the variation of demand response with several factors like the effects of time period, the length of the peak period, the climate, the history of pricing innovation in each market, the pattern of marketing dynamic pricing designs and the use of enabling technologies. They find that variation in the price ratio and the effect of enabling technologies are responsible for almost half of the variation in demand response. Wang et al (2011) study several smart gridenabled pricing programs and find that technology and greater price differentials enable better demand response. Roozbehani et al (2012) mention that demand response technologies and distributed generation increase the price elasticity of electricity along with the volatility of the system.

\section{Segmentation of electricity markets}

Segmentation of the electricity market helps in differentiating customers based on various attributes. Attributes of market segments are helpful in setting the range of prices or the time span for maintaining a certain price in a dynamic pricing environment. This section describes research on the basis of electricity market segmentation and focuses on the use of consumption level for segmentation. We also discuss lowincome groups as an important segment.

\section{Various bases of segmentation}

Electricity utilities generally segment their markets based on geographic boundaries. Moss and Cubed (2008) argue that segmentation schemes for residential customers should typically focus on attitudes and motivations. Yang et al (2013) refer to four consumer segments based on socio-demographic variables and attitude toward the adoption of green electricity in Denmark. A majority of consumers in all segments are ready to pay a higher price for green electricity. The authors observe that electricity market segmentation became ineffective because of three reasons-lack of comprehensive data, emphasis on technological solutions alone for demand-side management and a tendency to stay within the traditional broad industry segments of industrial, commercial and residential customers. Simkin et al (2011) mention that a 'bottom-up' analysis of customer attitudes, usage patterns, buying behavior and characteristics can be useful to develop segments. They develop a directional policy matrix from variables that represent market attractiveness and business capability and prioritize segments. Other factors like consumer service, green credentials, innovative tariffs and guarantee of no price inflation for a certain period also characterize energy market segments. Ifland et al (2012) develop a lifestyle typology and create three market segments based on consumption behavior, attitude toward energy consumption and enabling technologies, values and leisure time activities of consumers.

\section{Segmentation based on consumption data}

Segments can be based on consumption data. Panapakidis et al (2013) describe segmentation based on load patterns-high level and low level. The high-level segment includes geographical characteristics, voltage level and type of activity. The low-level segment is based on demographic characteristics, regulatory status, price management, universal service, fuel labeling supply and metering resolution. Clustering algorithms are required for further detailed categorization of segments. Varga and Czinege (2007) use discriminant analysis to characterize and classify consumers based on their load profiles. Hyland et al (2013) use smart meter data from Ireland and register the difference in gross margin earned by electricity suppliers from different types of consumers. This data help identify different possible market segments and the characteristics of the most profitable segmentation.

\section{Low-income group as a market segment}

A low-income group can be a market segment where the welfare viewpoint gains priority. These groups can be the worst affected in case of improper dynamic pricing implementation. Wood and Faruqui (2010) observe the effect of different pricing schemes on low-income consumers and find 
that critical peak pricing (CPP) is most effective in reducing bill amounts. They propose that the percentage of consumers benefiting from the schemes depends on the rate design itself. Faruqui et al (2012) study practical experiments of CPP and note that low-income groups reduced their electricity bills more than higher-income groups. Wolak (2010) also finds that low-income consumers are more sensitive to price signals than high-income ones. However, Wang et al (2011) state that lowincome customers have low price responsiveness. This is because they have fewer opportunities to reduce consumption due to unavailability of specific home appliances in which the energy consumption can be controlled. Governments need to take up the primary role in creating the conditions for segmentation both in regulated and in deregulated markets. Sharam (2005) notes that unethical welfare motives or improper administrative and regulatory control can bring out the troubles of segmentation in electricity markets. He identifies these ill-effects as redlining (discrimination of consumers in the market) and residual markets (suppliers misusing too much market power) which lead to exclusion and exploitation of some customers on financial or other bases.

\section{Consumption scheduling with dynamic prices}

Proper scheduling of electricity consumption in a dynamic pricing environment can flatten the load curve to a large extent. Chen et al (2013) develop an energy-efficient scheduling algorithm based on a time-varying pricing model. They use linear programming to obtain a deterministic scheduling solution and use an energy consumption adaptation variable to account for uncertainties. They use the day-ahead pricing data of Ameren Illinois Power Corporation as the input to their model and two sets of solar photovoltaic module of Kyocera Solar Incorporation as the solar energy source for the model. Their model achieves between 41 and $24 \%$ reduction of expenditure over traditional deterministic schemes and provides a schedule within 10 seconds. Agnetis et al (2013) identify various types of appliances with varying load types like shiftable, thermal, interruptible and non-manageable and then schedule their operations. The authors use a mixedinteger linear programming (MILP) model and a heuristic algorithm to solve the NP-hard problem. The objective functions are cost minimization and comfort maximization through scheduling preferences and climatic control. Wang et al (2013) present a novel traversal-and-pruning algorithm to schedule thermostatically controlled household loads to optimize an objective considering both expenditure and comfort. This algorithm has optimality, robustness, flexibility and speed. The authors propose that this algorithm can be useful in designing any automated energy management system.

Hubert and Grijalva (2012) incorporate electricity storage provisions in the scheduling problem by classifying loads as energy storage systems, non-interruptible loads and thermodynamic loads. They use MILP for robust optimized consumption scheduling to minimize the impact of stochastic inputs on the objective function. The objective function integrates electric, thermodynamic, economic, comfort and environmental parameters. Mishra et al (2013) observe that greedy charging algorithms when used at large scales shift the peaks causing grid instability. They present a storage adoption cycle incentivizing the use of energy storage at large scales with variable rates and peak demand surcharge. They show that consumers can flatten their demand by $18 \%$ of the minimum optimal capacity to flatten the grid demand of a centralized system.

Liu et al (2012) emphasize the maximum use of renewable resources in a load scheduling problem. Their model depends on weather forecasts. They classify appliances based on the type of energy consumption and assign dynamic priority in the scheduling process. Dupont et al (2012) state that the renewable energy tariff scheme can be used to increase renewable energy consumption during periods of high renewable energy generation. They use integer linear programming to optimize this scheduling problem taking into account customer preferences. This paper also emphasizes the use of automation in households for consumption scheduling over the year. Hu et al (2010) incorporate both active and reactive power demand and generation in the scheduling problem. The authors use a nonlinear load optimization method in a realtime pricing environment. The scheduling of consumption is studied for three customer groups-industrial, commercial and residential, and for three load periods—-peak load, flat load and off-peak load periods.

Scheduling in individual homes must be linked to the aggregate demand situation. Thus, it is necessary to model the individual household scheduling incorporating the aggregate demand. Kishore and Snyder (2010) point out that shifting the load from peak hours to off-peak hours in each household by means of a same price signal can shift the aggregate peak to the previously off-peak zone. Thus, the authors optimize electricity consumption within a home and across multiple homes. The in-home scheduling model attaches the probabilities of start and stop of operation of any appliance in the next time period. It also considers a cost for delay of start of operation. The model minimizes the total cost of electricity in a deterministic dynamic pricing environment. In the neighborhood-level scheduling model, the authors assume a wellcommunicated neighborhood where each household has a minimum guaranteed load at each time slot. The neighborhood, however, has a maximum limit of energy at each time slot. The idea is to distribute this available power to all households, thereby minimizing total costs. A second delay cost is introduced into the model to address the delay of starting an appliance after the specified maximum delay time. Luh et al (1982) present a 'load adaptive pricing' philosophy formulated as a closed-loop Stackelberg game. The authors demonstrate that a team optimum can be achieved through the proposed approach since the utility company can induce cooperative behavior from the customer. 
Table 4 Scheduling methods

Scheduling methods used

Linear programming

Traversal-and-pruning algorithm Priority scheduling algorithm Nonlinear programming Dynamic programming algorithm Closed-loop Stackelberg game
Paper reference

Li et al (2011), Hubert and Grijalva (2012), Dupont et al (2012), Cui et al (2012), Chen et al (2013), Agnetis et al (2013), Mishra et al (2013)

Wang et al (2013)

Liu et al (2012)

Hu et al (2010)

Kishore and Snyder (2010)

Luh et al (1982)
Li et al (2011) align individual optimality with social optimality by means of a distributed algorithm. Each customer has a utility function and provision for energy storage. This allows them to forecast their total individual demand for a future time after maximizing their individual benefit. The utility company collects these forecasts from all households and generates a price based on its cost function. This price is then published and the individual households reschedule their consumption. After several iterations, the consumption schedule of each household and the price offered by the utility gets fixed. Cui et al (2012) describe how scheduling of household loads helps electricity suppliers to maximize their profits and the global controller to maximize social welfare. The authors use greedy algorithm for the first model with pre-announced dynamic tariffs. They also devise a model for the utilities based on consumers' schedules. Table 4 shows the different scheduling methods used in the referenced literature.

\section{Conclusion}

Dynamic pricing of electricity is a demand-side management technique that is capable of stimulating demand response resulting in flatter load curves. There are several insights that can be developed with respect to peak load reduction, demand elasticity, market segmentation, pricing policy, enabling technology and customers' willingness to pay.

1. Peak load reduction of about $30 \%$ is registered in dynamic pricing pilots. Pricing experiments recorded $4 \%$ reduction to $8 \%$ increase in bill values. These figures can change depending on the pricing scheme and the attitude of the customers. Renewable energy consumption can further reduce bill values. A study estimated annual $\mathrm{CO}_{2}$ emission reduction of 5\% in a dynamically priced smart grid in the USA. However, emission reduction depends on the composition of the power generating units in use.

2. Electricity market data reveal that the demand elasticity for electricity is low in many markets, but other demographic and environmental factors can significantly enhance the response. For example, hot days and customers with high consumptions display better demand response.
3. Electricity market segmentation is necessary for effective pricing. Segmentation can be based on various demographic, behavioral and geographic factors as discussed in some studies. However, such segmentation is not implemented in practice and broad segments of industrial, commercial and residential are common.

4. There are several dynamic pricing schemes each of which can be a suitable policy depending on the market. RTP closely reflects wholesale prices, but it poses bill risk to the customers and requires technological support. Researchers propose that supporting programs to hedge the customers' risks need to be implemented along with dynamic pricing policies to enhance their acceptability among consumers.

5. Enabling technology significantly enhances demand response. Automation helps customers to respond quickly to changes in prices. Several consumption scheduling models using dynamic prices have been researched to understand the trade-off for customers between their expenditure and their comfort. Such models can help in actual implementation of dynamic prices by reducing manual scheduling tasks and risks of excessive expenditure.

6. Information on customers' willingness to pay is important while designing prices. Research shows that customers may be ready to pay 1.5 times more than the present prices for electricity. This value can vary from market to market.

Consumers and regulators need to be educated well on the benefits that dynamic pricing can bring to society without harming the interests of any stakeholder. The interest in this topic is developing, and there are ample opportunities opening up for the acceptance of this concept along with the wide implementation of smart grid technologies.

\section{Potential areas for future research}

There are open problems that can be interesting future research challenges. These are listed below.

(a) Understanding the customers' willingness to adopt dynamic tariffs can be very helpful for further progress in this field. This topic is an open research area that can 
be addressed to promote dynamic pricing to more number of customers and suppliers.

(b) There has been no research on estimating the demandprice relationship at microlevels. The most elastic portion of the demand curve indicates the phase when dynamic pricing can have the most impact. Factors influencing electricity demand change from consumer to consumer. Identification of such factors in different markets and the demand-price relationship is a potential research topic.

(c) Research on electricity market segmentation can enable better implementation of dynamic prices. Designing suitable pricing schemes for any market segment is an open research area.

(d) Optimization of prices, consumption schedules, number of market segments, use of energy storage and generation schedules are open research areas. There are earlier studies on these, but the developing smart grid scenarios offer possibilities of newer and better mathematical models.

(e) The environmental and social impacts of shifting from a flat rate tariff to a dynamic tariff scheme are worth studying in order to popularize the idea of dynamic pricing. Such studies are rare and have future research potential.

(f) Regulated markets can benefit from dynamic pricing from the welfare point of view. Research in this area is rare, and there are future research opportunities in the area of application of dynamic pricing in regulated markets. Appropriate ways to educate consumers and regulators about the benefits of dynamic pricing need to be identified and implemented.

Acknowledgements - The authors gratefully acknowledge financial support from Research and Publications Committee of Indian Institute of Management, Ahmedabad, and University Grants Commission, India.

\section{References}

Abreu J, Pereiray F, Vasconcelos J and Ferrao P (2010). An approach to discover the potential for demand response in the domestic sector. IEEE Conference on Innovative Technologies for an Efficient and Reliable Electricity Supply, Waltham, MA 2010: 240-245.

Agnetis A, de Pascale G, Detti P and Vicino A (2013). Load scheduling for household energy consumption optimization. IEEE Transactions on Smart Grid 4(4):2364-2373.

Akay D, Atak M (2007). Grey prediction with rolling mechanism for electricity demand forecasting of Turkey. Energy 32(9): $1670-1675$.

Allcott H (2009). Real time pricing and electricity markets. Harvard University. [online] Available at: http://www.erb.umich.edu/ HTML-Email/speakers/Post-docCandidates/documents/jmp-allcott. pdf [Accessed 18 Jan. 2016].

An L, Lupi F, Liu J, Linderman M and Huang J (2002). Modeling the choice to switch from fuelwood to electricity. Ecological Economics 42(3):445-457.
Borenstein S, (2007). Wealth transfers among large customers from implementing real-time retail electricity pricing. The Energy Journal 28(2):131-149.

Borenstein S. (2009). Time-varying retail electricity prices: theory and practice. In: Griffin J, Puller S (eds). Electricity Deregulation: Choices and Challenges, 4th edn. University of Chicago Press, Chicago, p. 317.

Borenstein S (2013). Effective and equitable adoption of opt-in residential dynamic electricity pricing. Review of Industrial Organization 42(2): 127-160.

Borenstein S and Holland S (2003). On the efficiency of competitive electricity markets with time-invariant retail prices (No. w9922). National Bureau of Economic Research., Working Paper Series. Available at: http://escholarship.org/uc/item/2k54m0zk\#page-1 [Accessed 21 Sep. 2016].

Borenstein S, Jaske M, and Rosenfeld A (2002). Dynamic pricing, advanced metering, and demand response in electricity markets. Center for the Study of Energy Markets. Available at: https:// escholarship.org/uc/item/11w8d6m4 [Accessed 21 Sep. 2016].

Bose R and Shukla M (1999). Elasticities of electricity demand in India. Energy Policy 27(3):137-146.

Braithwait S (2010). Behavior modification. Power and Energy Magazine, IEEE 8(3):36-45.

Catalão JPS, Mariano SJPS, Mendes VMF and Ferreira LAFM (2006). Application of neural networks on next-day electricity prices forecasting. In: Proceedings of the 41st International Universities Power Engineering Conference, IEEE, Newcastle upon Tyne, UK, (Vol. 3, pp. 1072-1076).

Celebi E and Fuller J (2012). Time-of-use pricing in electricity markets under different market structures. IEEE Transactions of Power Systems 27(3):1170-1181.

Charles River Associates (2005). Applications of dynamic pricing in developing and emerging economies. [online] The World Bank. Available at: http://siteresources.worldbank.org/INTENERGY/ Resources/ApplicationsofDynamicPricing.pdf [Accessed 8 Jan. 2016].

Chen X, Wei $\mathrm{T}$ and $\mathrm{Hu}$ S (2013). Uncertainty-aware household appliance scheduling considering dynamic electricity pricing in smart home. IEEE Transactions on Smart Grid 4(2):932-941.

Cia.gov. (2016). The World Factbook. [online] Available at: https:// www.cia.gov/library/publications/resources/the-world-factbook/ rankorder/2236rank.html [Accessed 22 Mar. 2016].

Contreras J, Espinola R, Nogales FJ and Conejo AJ (2003). ARIMA models to predict next-day electricity prices. IEEE Transactions on Power Systems, 18(3):1014-1020.

Costello K (2004). An observation on real-time pricing: Why practice lags theory. The Electricity Journal 17(1):21-25.

Cui T, Goudarzi H, Hatami S, Nazarian S and Pedram M (2012). Concurrent optimization of consumer's electrical energy bill and producer's power generation cost under a dynamic pricing model. In: 2012 IEEE PES Innovative Smart Grid Technologies (ISGT), Washington, DC, 2012, pp. 1-6.

David A and Wen F (2000). Strategic bidding in competitive electricity markets: A literature survey. In: Power Engineering Society Summer Meeting, 2000. IEEE (Vol. 4, pp. 2168-2173).

David AK and Li YZ (1993). Effect of inter-temporal factors on the real time pricing of electricity. IEEE Transactions on Power Systems 8(1):44-52.

Desai K and Dutta G (2013). A dynamic pricing approach to electricity prices in the Indian context. International Journal of Revenue Management 7(3/4):268-288.

Devicienti F, Irina K and Stefano P. (2005). Willingness to pay for water and energy: an introductory guide to contingent valuation and coping cost techniques. Energy and Mining Sector Board, 3. World Bank. Available at: http://documents.worldbank.org/ 
curated/en/866831468158995793/Willingness-to-pay-for-waterand-energy-an-introductory-guide-to-contingent-valuation-andcoping-cost-techniques [Accessed 21 Sep. 2016].

Dupont B, Jeroen T and Ronnie B (2012). Automated residential demand response based on dynamic pricing. 2012 3rd IEEE PES International Conference and Exhibition on Innovative Smart Grid Technologies (ISGT Europe), Berlin, 2012, pp. 1-7.

Eia.gov. (2016). U.S. Energy Information Administration (EIA)— Source. [online] Available at: http://www.eia.gov/forecasts/ capitalcost/ [Accessed 22 Mar. 2016].

Faruqui A (2010). The ethics of dynamic pricing. The Electricity Journal 23(6):13-27.

Faruqui A (2012). November. Implementation of dynamic pricing: Trends and debates. In: 5th Forum Latino-Americano de Smart Grid. Sao Paulo, Brazil.

Faruqui A and Lessem N (2012). Managing the benefits and costs of dynamic pricing in Australia. Prepared for the Australian Energy Market Commission (AEMC). [online] Available at: http://www. aemc.gov.au/Media/docs/Managing-the-Benefits-and-Costs-ofDynamic-Pricing-09-15-12-45e4ddd9-98b6-4589-a71b-dd121caced 9c-1.PDF [Accessed 12 Jan. 2016].

Faruqui A and Sergici S (2009). Household response to dynamic pricing of electricity - a survey of the experimental evidence. Available at: http://www.hks.harvard.edu/hepg/Papers/2009/The\% 20Power\%20of\%20Experimentation\%20_01-11-09_.pdf [Accessed 28 Oct. 2015].

Faruqui A and Sergici S (2013). Arcturus: International evidence on dynamic pricing. The Electricity Journal 26(7):55-65.

Faruqui A and Palmer J (2012). The discovery of price responsiveness-A survey of experiments involving dynamic pricing of electricity. Available at http://papers.ssrn.com/sol3/papers.cfm? abstract_id=2020587\&download=yes. [Accessed 21 Sep. 2016].

Faruqui A, Hledik R and Sergici S (2009). Piloting the smart grid. The Electricity Journal 22(7):55-69.

Faruqui A, Hledik R and Palmer J (2012). Time-varying and dynamic rate design. Regulatory Assistance Project. Available at: http://www. raponline.org/wp-content/uploads/2016/05/rap-faruquihledikpalmertimevaryingdynamicratedesign-2012-jul-23.pdf [Accessed 21 Sep. 2016].

Faruqui A, Sergici S and Akaba L (2014). The impact of dynamic pricing on residential and small commercial and industrial usage: New experimental evidence from Connecticut. The Energy Journal 35(1):137-160.

Faruqui A, Sergici S and Wood L (2009). Moving toward utility-scale deployment of dynamic pricing in mass markets. IEE Whitepaper, June. Available at: http://www.edisonfoundation.net/iei/Documents/ IEE_Utility-ScaleDynamicPricing_0609.pdf [Accessed 21 Sep. 2016].

Filippini M and Pachauri S (2004). Elasticities of electricity demand in urban Indian households. Energy Policy 32(3):429-436.

Garamvolgyi M and Varga L (2009). Electricity pricing in liberalized market using consumer characterization. In: 2009. EEM 2009, 6th International Conference on the European Energy Market. Leuven, 2009, pp. 1-6.

Gerpott T and Paukert M. (2013). Determinants of willingness to pay for smart meters: An empirical analysis of household customers in Germany. Energy Policy 61:483-495.

Giulietti M, Grossi L and Waterson M (2010). Price transmission in the UK electricity market: Was NETA beneficial? Energy Economics 32(5):1165-1174.

Han X, Luh P, Yan J and Stern G (2010). Payment cost minimization with transmission capacity constraints and losses using the objective switching method. In: IEEE PES General Meeting, Minneapolis, MN, 2010, pp. 1-8.
Harris C (2006). Electricity markets: Pricing, structures and economics. NJ: Wiley.

Hledik R (2009). How green is the smart grid? The Electricity Journal 22(3):29-41.

Holland S and Mansur E (2008). Is real-time pricing green? The environmental impacts of electricity demand variance. Review of Economics and Statistics 90(3):550-561.

Holtschneider T and Erlich I (2013). Optimization of electricity pricing considering neural network based model of consumers' demand response. In: 2013 IEEE Symposium on Computational Intelligence Applications in Smart Grid (CIASG), Singapore, 2013, pp. 154-160.

$\mathrm{Hu}$ W, Chen Z and Bak-Jensen B (2010). Impact of optimal load response to real-time electricity price on power system constraints in Denmark. In: 45th International Universities Power Engineering Conference. (UPEC), Cardiff, Wales, 2010, pp. 1-6.

Hubert T and Grijalva S (2012). Modeling for residential electricity optimization in dynamic pricing environments. IEEE Transactions on Smart Grid 3(4):2224-2231.

Hyland M, Leahy E and Tol RS (2013). The potential for segmentation of the retail market for electricity in Ireland. Energy Policy 61:349-359.

Hyndman R. and Fan S (2010). Density forecasting for long-term peak electricity demand. IEEE Transactions on Power Systems 25(2):1142-1153.

Ifland M, Exner N, Doring N and Westermann D (2012). Influencing domestic customers' market behavior with time flexible tariffs. In: 2012 3rd IEEE PES Innovative Smart Grid Technologies Europe (ISGT Europe), Berlin, 2012, pp. 1-7.

Johnsen TA and Jess-Olsen O (2008). The relationship between wholesale and retail electricity prices to households in the Nordic countries. University of Vaasa, VaasaEMG. Available at: http:// citeseerx.ist.psu.edu/viewdoc/download?doi=10.1.1.471.425\&rep= rep1\&type=pdf [Accessed 21 Sep. 2016].

Joskow P and Wolfram C (2012). Dynamic pricing of electricity. The American Economic Review 102(3):381-385.

Kaluvala NS and Forman A (2013). Smart grid. International Journal of E-Politics (IJEP) 4(2):39-47.

Kekatos V, Veeramachaneni S, Light M and Giannakis GB (2013). Day-ahead electricity market forecasting using kernels. In: 2013 IEEE PES Innovative Smart Grid Technologies (ISGT), Washington, DC, 2013, pp. 1-5.

Kirschen DS (2003). Demand-side view of electricity markets. IEEE Transactions on Power Systems 18(2):520-527.

Kirschen DS, Strbac G, Cumperayot P and de Paiva Mendes D (2000). Factoring the elasticity of demand in electricity prices. IEEE Transactions on Power Systems 15(2):612-617.

Kishore S and Snyder LV (2010). Control mechanisms for residential electricity demand in smartgrids. In: 2010 First IEEE International Conference on Smart Grid Communications (Smart Grid Comm), Gaithersburg, MD 2010, pp. 443-448.

Kok G, Shang K and Yucel S (2014). Impact of electricity pricing policy on renewable energy investments and carbon emissions. Available at: http://home.ku.edu.tr/ gkok/papers/renewable.pdf [Accessed 21 Sep. 2016].

Krause T and Andersson G (2006). Evaluating congestion management schemes in liberalized electricity markets using an agentbased simulator. In: 2006 IEEE Power Engineering Society General Meeting, Montreal, Que., 2006. doi:10.1109/PES.2006. 1709123.

Letzler R (2007). Implementing opt-in, residential, dynamic electricity pricing: Insights from economics and psychology. ProQuest.

Li N, Chen L and Low SH (2011). Optimal demand response based on utility maximization in power networks. In: 2011 IEEE Power and Energy Society General Meeting, Detroit, MI, USA, 2011, pp. 1-8. 
Li R, Chen L and Yokoyama R (2003). A methodology for evaluating the wholesale/retail prices in deregulation market. In: Power Tech Conference Proceedings, 2003 IEEE Bologna (Vol. 1, pp. 7).

Li C, Svoboda A, Xiaohong G and Singh H (1999). Revenue adequate bidding strategies in competitive electricity markets. IEEE Transactions on Power Systems 14(2):492-497.

Liu X, Ivanescu L, Kang R and Maier M (2012). Real-time household load priority scheduling algorithm based on prediction of renewable source availability. IEEE Transactions on Consumer Electronics 58(2):318-326.

Luh P, Ho Y and Muralidharan R (1982). Load adaptive pricing: An emerging tool for electric utilities. IEEE Transactions on Automatic Control 27(2):320-329.

Mak J and Chapman B (1993). A survey of current real-time pricing programs. The Electricity Journal 6(7):76-77.

Mandal P, Senjyu T, Urasaki N, Funabashi T and Srivastava AK (2006). Electricity price forecasting for PJM Day-ahead market. In: 2006 IEEE PES Power Systems Conference and Exposition, Atlanta, GA, 2006, pp. 1321-1326.

McDonald JR and Lo KL (1990). Dynamic price structures and consumer load reaction. In: Sixth International Conference on Metering Apparatus and Tariffs for Electricity Supply, IET, Manchester, April, 1990, pp. 6-10.

McSharry P, Bouwman S and Bloemhof G (2005). Probabilistic forecasts of the magnitude and timing of peak electricity demand. IEEE Transactions on Power Systems 20(2):1166-1172.

Mirasgedis S, Sarafidis Y, Georgopoulou E, Lalas D, Moschovits M, Karagiannis F and Papakonstantinou D (2006). Models for midterm electricity demand forecasting incorporating weather influences. Energy 31(2-3):208-227.

Mirza FM and Bergland O (2012). Pass-through of wholesale price to the end user retail price in the Norwegian electricity market. Energy Economics 34(6):2003-2012.

Mishra A, Irwin D, Shenoy P and Zhu T (2013). Scaling distributed energy storage for grid peak reduction. In: Proceedings of the Fourth International Conference on Future energy systems. ACM, January, 2013, pp. 3-14.

Moss SJ, Cubed M and Fleisher K (2008). Market segmentation and energy efficiency program design. Berkeley, California Institute for Energy and Environment. Available at: http://citeseerx.ist.psu. edu/viewdoc/download?doi=10.1.1.473.4164\&rep=rep1\&type=pdf [Accessed 21 Sep. 2016].

Nogales FJ, Contreras J, Conejo AJ and Espínola R (2002). Forecasting next-day electricity prices by time series models. IEEE Transactions on Power Systems 17(2):342-348.

Oseni M (2013). Paying for improved electricity services in developing countries: Any role for previous mitigation action? Available at: http://www.usaee.org/usaee2014/submissions/OnlineProceedings/ MUSILIU\%20OSENI\%20PHD\%20SECOND\%20YEAR\%20REP ORT\%20PROOF\%20READ\%20PAPER\%202_IAEE.pdf [Accessed 29 Jun. 2015].

Ozbafli A and Jenkins G (2013). Estimating willingness to pay for reliable electricity supply: A choice experiment study. Available at: http:// www.queensjdiexec.org/publications/qed_dp_224.pdf [Accessed 26 Jun. 2015].

Pagani G and Aiello M (2015). Generating realistic dynamic prices and services for the smart grid. IEEE Systems Journal 9(1): 191-198

Panapakidis IP, Alexiadis MC and Papagiannis GK (2013). Deriving the optimal number of clusters in the electricity consumer segmentation procedure. In: 2013 10th International Conference on the European Energy Market (EEM), Stockholm, 2013, pp. 1-8.

Quillinan JD (2011). Pricing for retail electricity. Journal of Revenue \& Pricing Management 10(6):545-555.
Roozbehani M, Dahleh MA and Mitter SK (2012). Volatility of power grids under real-time pricing. IEEE Transactions on Power Systems 27(4):1926-1940.

Saravanan S, Kannan S and Thangaraj C (2012). India's electricity demand forecast using regression analysis and artificial neural networks based on principal components. ICTACT Journal on Soft Computing 2(4):36.

Seetharam DP, Ganu T and Basak J (2012). Sepia-A self-organizing electricity pricing system. IEEE PES Innovative Smart Grid Technologies, Tianjin, 2012, pp. 1-6.

Shaikh SKM and Dharme AA (2009). Time of use pricing-India, a case study. International Conference on Power Systems, 2009. ICPS'09. Kharagpur, December, 2009, pp. 1-6.

Sharam A (2005). Market segmentation and domestic electricity supply in Victoria (Doctoral dissertation, Swinburne University of Technology).

Simkin L and Dibb S (2011). Segmenting the energy market: problems and successes. Marketing Intelligence \& Planning 29(6):580-592.

Simshauser P and Downer D (2014). On the inequity of flat-rate electricity tariffs. AGL Applied Economic and Policy Working Paper, (41). Available at: http://aglblog.com.au/wp-content/ uploads/2014/07/No.41-On-the-inequity-of-tariffs.pdf [Accessed 21 Sep. 2016].

Skantze P, Ilic M and Chapman J (2000). Stochastic modeling of electric power prices in a multi-market environment. Power Engineering Society Winter Meeting, 2000. IEEE (Vol. 2, pp. 1109-1114).

Stephenson P, Lungu I, Paun M, Silvas I and Tupu G (2001). Tariff development for consumer groups in internal European electricity markets. In: Electricity Distribution, 2001. Part 1: Contributions. CIRED. 16th International Conference and Exhibition on IET (IEE Conf. Publ No. 482) (Vol. 5, pp. 5).

Taylor J (2003). Short-term electricity demand forecasting using double seasonal exponential smoothing. Journal of the Operational Research Society 54(8):799-805.

Taylor J (2010). Triple seasonal methods for short-term electricity demand forecasting. European Journal of Operational Research 204(1):139-152.

Taylor J, de Menezes L and McSharry P (2006). A comparison of univariate methods for forecasting electricity demand up to a day ahead. International Journal of Forecasting 22(1):1-16.

Thimmapuram PR and Kim J (2013) Consumers' price elasticity of demand modeling with economic effects on electricity markets using an agent-based model. IEEE Transactions on Smart Grid 4(1):390-397.

Tiwari P (2000). Architectural, demographic, and economic causes of electricity consumption in Bombay. Journal of Policy Modeling 22(1):81-98.

Twerefou D (2014). Willingness to pay for improved electricity supply in Ghana. Modern Economy 5(5):489-498.

Varga L and Czinege K (2007). Electricity consumer characterization in liberalized market based on data mining techniques. In: 42nd International Universities Power Engineering Conference, 2007. UPEC 2007. Brighton, 2007, pp. 78-82.

Wang C, Zhou Y, Wang J and Peng P (2013). A novel traversal-andpruning algorithm for household load scheduling. Applied Energy 102:1430-1438.

Wang J, Biviji MA and Wang WM (2011). Lessons learned from smart grid enabled pricing programs. In: Power and Energy Conference at Illinois (PECI), 2011 IEEE, Champaign, IL, pp. 1-7.

Wang J, Zhu W, Zhang W and Sun D (2009). A trend fixed on firstly and seasonal adjustment model combined with the $\hat{I} \mu-S V R$ for short-term forecasting of electricity demand. Energy Policy 37(11):4901-4909. 
Weber J and Overbye T (1999). A two-level optimization problem for analysis of market bidding strategies. In: Power Engineering Society Summer Meeting. Conference Proceedings (Cat. No.99CH36364), 1999 IEEE, Edmonton, Alta., 2:682-687.

Wolak FA (2010). An experimental comparison of critical peak and hourly pricing: the PowerCentsDC program. Department of Economics Stanford University. Available at: http://web.stanford.edu/ group/fwolak/cgi-bin/sites/default/files/files/An\%20Experimental\% 20Comparison $\% 20$ of $\% 20$ Critical $\% 20$ Peak $\% 20$ and $\% 20$ Hourly $\% 20$ Pricing_March\%202010_Wolak.pdf [Accessed 21 Sep. 2016].

Wolak FA (2011). Do residential customers respond to hourly prices? Evidence from a dynamic pricing experiment. The American Economic Review, Wolak FA (2011). Do residential customers respond to hourly prices? Evidence from a dynamic pricing experiment. The American Economic Review 101(3):83-87.

Wood L and Faruqui A (2010). Dynamic pricing and low-income customers. Public Utilities Fortnightly 148(11):60-64.

Yang Y, Haider W and Solgaard HS (2013). Accounting for preference heterogeneity among residential energy consumers. In: 2013 10th International Conference on the European Energy Market (EEM), Stockholm, 2013, pp. 1-7.

Zareipour H, Cañizares CA, Bhattacharya K and Thomson J (2006). Application of public-domain market information to forecast
Ontario's wholesale electricity prices. IEEE Transactions on Power Systems 21(4):1707-1717.

Zhang D, Wang Y and Luh PB (2000). Optimization based bidding strategies in the deregulated market. IEEE Transactions on Power Systems 15(3):981-986.

Zhao F, Luh P, Yan J, Stern G and Shi-Chung C (2010). Bid cost minimization versus payment cost minimization: A game theoretic study of electricity auctions. IEEE Transactions on Power Systems 25(1):181-194.

Zhao F, Luh P, Yan J, Stern G and Shi-Chung C (2008). Payment cost minimization auction for deregulated electricity markets with transmission capacity constraints. IEEE Transactions on Power Systems 23(2):532-544.

Zhou P, Ang B and Poh K (2006). A trigonometric grey prediction approach to forecasting electricity demand. Energy 31(14): 2839-2847.

Zhou S and Teng F (2013). Estimation of urban residential electricity demand in China using household survey data. Energy Policy 61:394-402.

Received 17 August 2015; accepted 8 November 2016 